\title{
AEROGENERADORES EN GALICIA: MONTES CRUCIFICADOS, PAISAJE ARRUINADO, ENERGÍA QUE NO VA
}

\section{TURBINES IN GALICIA: MONTES CRUCIFIED, RUINED \\ LANDSCAPE, ENERGY IS NOT}

Xesús López Fernández: Ibérica2000

xesus-lopez@iberica2000.org

\section{CURRÍCULUM VITAE DE CADA AUTOR}

Colaborador del colectivo ecologista www.iberica2000.org. Es una herramienta en Internet creada por el Centro de Investigaciones y Promoción de Iniciativas para Conocer y Proteger la Naturaleza, organización sin ánimo de lucro que ha sido financiada con la ayuda de más de 12.000 socios simpatizantes de toda España.

\section{RESUMEN}

Un aerogenerador es un generador eléctrico movido por una turbina accionada por el viento. Los aerogeneradores pueden trabajar de manera aislada o agrupados en parques eólicos. La energía eólica se está volviendo más popular en la actualidad, al haber demostrado la viabilidad industrial. Por eso, en Galicia se instalaron unos 2400. Pero han resultado inservibles porque además se han instalado en zonas que afean el precioso paisaje de los montes gallegos. El negocio escandaloso de los aerogeneradores continúa a día de hoy. Sin duda habría que revisar el trabajo y enriquecerlo con noticias de actuaciones y decisiones políticas que se han ido produciendo desde su redacción. 


\section{PALABRAS CLAVE}

Aerogenerador - Galicia - Paisaje - Política

\section{ABSTRACT}

A wind turbine is an electrical generator driven by a turbine driven by wind. Wind turbines can work in isolation or grouped in wind farms. Wind energy is becoming more popular today, having demonstrated the industrial feasibility. Therefore, in Galicia were installed about 2400. But have proved useless because in addition have been installed in areas that disfigure the beautiful scenery of the mountains in Galicia. The business scandal of the wind continues to this day. No doubt it would work to revise and enrich it with news of activities and policy decisions that have taken place since its drafting.

\section{KEY WORDS}

Wind Turbine - Galicia - Landscape - Politics

\section{TEXTO:}

A Galicia hace algún tiempo que ha llegado el escándalo de la nueva energía. Ahora ha cundido la voz de alarma: Porque parece que 2.400 molinos de viento instalados no sirven. La noticia dada en ese sentido fue después rectificada por la de que habría que revisarlos, mejorarlos, ponerles parches o sabe Dios qué. Pero algunos ya hicieron el gran negocio y con apenas capital, al vender sus concesiones. 
Desde los primeros y anecdóticos molinos de viento que aparecieron en el paisaje gallego se dio en hablar de energía limpia, sin impacto, y sólo después de varios años de experiencia de la nueva energía se ha empezado a cuestionar este tipo de desarrollo. Se ha comenzado a hablar incluso de fracaso.

En Galicia deberán ser renovados, reparados o mejorados unos 2.400, en clara sintonía con el mensaje de los escépticos, que intuían que la "nueva" energía no iba, que detrás de todo el tinglado publicitario había un fondo de estafa... que cada día parece más evidente.

Es sabido el caso de Dinamarca, que ha optado por no autorizar nuevos parques eólicos. Y también la Xunta de Galicia asume que los mismos, traducidos en "montes crucificados", al proliferar en demasía afean excesivamente el paisaje...

El gobierno autónomo de Galicia quiere frenar la implantación de aerogeneradores que autorizó con demasiada alegría en zonas altas del territorio gallego y buscar puntos alternativos para la implantación de un nuevo modelo territorial, con el objetivo de mostrar un paisaje más atractivo, algo difícil de creer cuando todavía se muestran ávidos de acabar con la vegetación clímax del país, afanados en convertir todo lo que la vista contempla en eucaliptal puro y duro cuando no en urbanizaciones de costa, trasladando a esta tierra la maldición tan frecuente en el Levante español.

Ya digo, difícil de digerir la promesa de un nuevo modelo territorial o de que van a cuidar el litoral, que poco les importa. Seguro.

Y como aclaración de la confusión existente, de la ignorancia con que se gobierna creemos oportuno denunciar la instalación de aerogeneradores en las proximidades de Cabo Vilán..., espacio comprendido en la Red Natura y al que el número 1.495 de 
la revista Intervíu del 20.12.2004 dedicaba un artículo sobre posible corrupción, por haberse instalado en el mismo una granja de rodaballos, después de haber sido expoliados, engañados, los anteriores propietarios de algunos terrenos, vendidos en algún caso a razón de $1 €$ el metro cuadrado, extorsionados los anteriores dueños con la amenaza de posible expropiación.

Y para mayor vergüenza, el señor Fraga inauguró la tal granja, de capital extranjero, mostrando aquel espacio como la "nueva fachada marítima" de un entorno sagrado, perdida ya por este hombre la memoria histórica de nuestro patrimonio natural.

Creo oportuno también mencionar la noticia de La Voz de Galicia, (26.1.2005), en la que se habla del viaje a Europa de un vicepresidente de la Xunta, que es también conselleiro de Medio Ambiente. Claro, están preocupadas nuestras autoridades porque se ha puesto en evidencia la contaminación generada por las centrales térmicas, pero de la lectura de lo que trae La Voz se deduce que están más preocupadas, obsesionadas, por obtener más fondos de cohesión para la Red Natura. ¿Para qué? ¿Para cargarse Touriñán como ya han hecho con Cabo Vilán? ¿Para privatizar todavía más litoral? ¡Qué peligro representa esta gente que nos gobierna!.

Las comunidades de montes en mano común deben de tener a estas alturas de la película muchísima información sobre el esfuerzo privatizador de la Xunta para posibilitar la instalación de parques eólicos, después de tanto tiempo burladas...

Una vergüenza.

Porque con las concesiones otorgadas habrán puenteado, en más de una ocasión, la propiedad vecinal de la inmensa mayoría de los montes gallegos, algo que se ha mantenido como figura consuetudinaria desde el tiempo de los suevos. 
Los propietarios burlados, expoliados, definen las actuaciones llevadas a cabo sin su consentimiento (instalación de molinos de viento o "virandelos", la actuación de las palas excavadoras o las repoblaciones forestales no convenientes) como otros "prestiges", como en el caso de una denuncia promovida por una señora de Muras ante la Unión Europea...

La denuncia de dicha señora se refería a la presunta ilegalidad de tres parques eólicos instalados en la sierra del Xistral, zona protegida por la Red Natura. La denuncia fue promovida después de diversos requerimientos sin resultado, ante la Xunta de Galicia, por existir en la zona tres hábitats de interés comunitario.

Como siempre, la Xunta manifestaba actuar de acuerdo con la ley. Sí, pero los accesos a dos de esos parques afectaron al nacimiento del río Eume, según pudo verificar el Seprona... E igualmente al río Landro.

Téngase presente que la denunciante acudió a la Unión Europea después de haber recurrido ante el Tribunal Superior de Justicia de Galicia contra la instalación de dichos parques, además de promover un proceso penal, incoado en Santiago por un presunto delito contra el medio ambiente.

Aún cuando parece que estamos lejos de tener conciencia clara del problema, de la picaresca que se esconde algunas veces tras la concesión de nuevos parques, parece que la cuestión está ya en un punto de no retorno con el ejemplo citado de Dinamarca, con su decisión de no promover nuevas "repoblaciones" de aerogeneradores, porque siendo el país que más rendimiento le ha sacado (el 15\% de su energía es de origen eólico), no han sido capaces de frenar la emisión de CO2.

Está cuestionada, pues, la energía producida por el viento. Y las acusaciones que se lanzan desde diversos colectivos y países parecen justificadas. En Valencia 
denuncian ahora la instalación de 2.700 turbinas que sólo van a crear un puñado de puestos de trabajo duraderos, además de costar una fortuna en subvenciones, duplicar la factura de la luz y no servir para nada.

Noticia de LEVANTE (El Mercantil Valenciano), fechada en Cocentaina el 6.1.2005, daba cuenta de la protesta que está llevando a cabo la coordinadora del Plan Eólico, que había solicitado entrevista a Narbona con el fin de evitar la instalación de aerogeneradores en el Comtat.

También se han dirigido a los alcaldes de la zona, a los que han pedido denieguen nuevas instalaciones y recordado que son ellos los que tienen más autoridad moral para impedir que progrese el destrozo ambiental que la excesiva proliferación de aerogeneradores implicaría. En cuanto a la mortandad de aves, es especialmente grave la falsificación de informes que se denuncia en Navarra.

Y siguen los velencianos: aquí estamos machacando el paisaje, desertizando el país y acabando con el turismo rural, además de matar aves y enloquecer a los vecinos cercanos a los parques; degradando la calidad de vida de las gentes para producir menos energía que una sola planta moderna de ciclo combinado de gas, sin subvenciones ni costes escondidos, que de todas formas habrá que construir o mantener vivas las existentes como reservas activas para los días sin viento.

Tema largo. Los curiosos pueden consultar en la "red" y en los trabajos de Mark Duchamp, una autoridad mundial en la materia que hace mención a otras fuentes de energía más limpias que la eólica y más pensadas hacia el desarrollo sostenible: energías geotérmicas, hidrógeno, solar, olas y mareas, y otras.

Alguno de los trabajos consultados para esta corta aproximación al tema están ilustrados con fotografías de aves muertas, cortadas o desgarradas por los 
aerogeneradores. Para las águilas, pigargos (áquilas marinas), buites, ánades y tantas otras especies Mark Duchamp intuye que nuestros nietos solamente podrán verlas únicamente fuera de su medio, en zoológicos.

Y el autor pone en evidencia el contrasentido que se da en la Gran Bretaña, donde está prohibido cazar áquilas, al otorgar licencias para instalaciones de aerogeneradores, lo que implica una autorización para matarlas aunque esté prohibido por ley...

Una contradicción del poder, que muchas veces no alcanza a ver hasta que los ecologistas denuncian. O que lo hace una señora en Muras, Lugo, que al parecer sabe, como otras mujeres, que estas denuncias tienen que acabar en la Unión Europea.

Duchamp se pregunta, de todas formas, para qué valen las leyes y directivas europeas, o a quién le va a gustar vivir sumergido en un gran polígono industrial, además de que, con el frenesí demostrado hacia la energía eólica, estamos frenando el posible desarrollo de otras energías.

Y los montes, como ya sabemos, cada vez más crucificados.

El negocio escandaloso de los aerogeneradores continúa a día de hoy. Sin duda habría que revisar el trabajo y enriquecerlo con noticias de actuaciones y decisiones políticas que se han ido produciendo desde su redacción.

Añado, si acaso, tres noticias de esta misma fecha. La primera ha sido publicada en La Opinión, de La Coruña: 
la Xunta deberá aclarar las concesiones otorgadas a la familia del señor Francisco Vázquez, ex-alcalde de la ciudad y ahora embajador ante la Santa Sede, presuntamente implicado, también, en ciertas tramas urbanísticas.

Las segunda y tercera aportaciones son nuevas recogidas de La Voz de Galicia de esta fecha y se refieren a: paralización de minihidráulicas y molinos de viento , lo que parece una noticia esperanzadora, y la noticia sobre la adjudicación de 80 nuevos parques eólicos, que parece ampliar el feísmo paisajístico, la geografía del horror, como se evidencia por medio de la foto que acompaña a la noticia. Pero en el origen del horror ha habido tráfico de influencias, presuntas corrupciones políticoempresariales, como las que La Opinion, de la Coruña, nos brinda con fecha 23.2.2006 en relación con la cesión de derechos eólicos de Endesa a empresas del cuñado del Director Xeral de Urbanismo, periódico al que no conviene perder la pista porque es el que, de momento, está ofreciendo más información comprometida. Comprometidos con la información, como parecen estar, puesto que han sido los que han informado más puntualmente del presunto tráfico de influencias existente en el entorno Paco Vázquez, una de las posibles razones de su ascenso a embajador español en El Vaticano.

Y con fecha 24.2.2006 vuelve la Opinión de La Coruña a ofrecernos nueva noticia sobre el escándalo de las eólicas, sobre el pasteleo de las influencias y corrupciones, para con fecha 25.2.2006 sacar a la luz un nuevo escándalo, la cesión de un parque eólico por un concello del PP, el de Ourol, al señor Fontenla, jefe de la patronal gallega, cuya relación con Paco Vázquez tuvo éste buen cuidado de ocultar ante el Senado. Ya solo falta que se concreten ante la Justicia algunas acusaciones, y que la Justicia, como en Canarias, funcione, como se deduce de la información dada por La Voz de Galicia con fecha 2.02.2006 . 
Con fecha 4.3.2006, diversos medios informan de que el Fiscal ha solicitado a la Xunta información sobre las licencias energéticas otorgadas por la Xunta del PP. ¿Estaremos ante una actuación relevante, con un fiscal que ejerza como verdadero defensor del ciudadano, o será una actuación más a diluir con el tiempo?

La Voz de Galicia del 5.3.2006 aclara lo que al comienzo del trabajo denominábamos como "fondo de estafa", porque la energía eólica instalada podría quintuplicarse a día de hoy con la renovación de las instalaciones.Y también La Opinión de la misma fecha incide sobre el tema, claros y contundentes, según la noticia, los argumentos presentados por el conselleiro de Industria en el Parlamento de Galicia. Tibio el PSOE y defensores a ultranza de Paco Vázquez las gentes del PP. ¿Qué está pasando que aparecen como maridados PP y PSOE, el núcleo duro del sistema de influencias? Y el 6.3.2006 es nuevamente La Opinión de La Coruña la que informa de la ignorancia del alcalde de Ourol en relación con el negocio del aire de la familia del ex-alcalde coruñés, a la que pertenece el parque eólico asentado en montes con memoria histórica de bandidos (Manuel Casanova, Luís Trigo) que allí se guarecían.

La Voz de Galicia últimas noticias del 7.3.2006. Dice de que el Fiscal todavía no ha recibido el informe de la Xunta sobre las concesiones, en las que se supone existe información privilegiada, trato de favor o, simplemente, corrupción. 